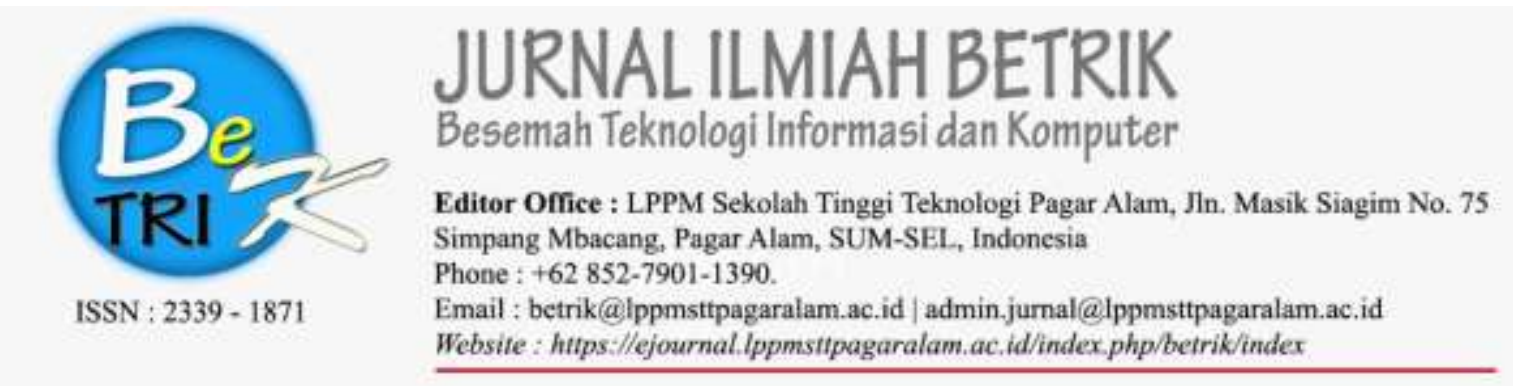

\title{
WEBSITE PENERIMAAN SISWA BARU SMP PERSATUAN REPUBLIK INDONESIA (PGRI) KOTA PAGARALAM
}

\author{
Desi Puspita \\ Dosen Teknik Informatika Sekolah Tinggi Teknologi Pagaralam \\ Jalan Masik Siagim No.75 Simpang Macang Kec.Dempo Tengah Pagar Alam \\ Sur-el:desi_ofira@yahoo.com.
}

\begin{abstract}
The new admissions website at SMP PGRI Pagaralam is still done manually, that is the acceptance of new students have not used the programming language, where the new student acceptance is still recorded in the big books, so the peroses of service on the acceptance of new students become slow and ineffective. Results and this study is a new admissions system that has been asked directly at SMP PGRI Pagaralam City. This system is built using Macromedia Dreamweaver CS3 application, programming languages PHP and MySQL, while the system development method is Web ngineering. From the research it can be concluded that to create a new student admissions website that must be done first is to create a new admissions website. If the new admissions system is built is able to input new student admissions data and generate output in the form of reports then it can be concluded that the new admissions website SMP PGRI Pagaralam Pagaralam successful.
\end{abstract}

Keywords: New Student Admissions Website SMP PGRI Pagaralam, Web Ngineering.

\begin{abstract}
Abstrak:Website penerimaan siswa baru pada SMP PGRI Kota Pagaralam masih dilakukan secara manual, yaitu penerimaan siswa baru belum mengunakan bahasa pemerograman , dimana penerimaan siswa baru masih dicatat pada buku-buku besar, sehingga peroses pelayanan pada penerimaan siswa baru menjadi lambat dan tidak efektif. Hasil dan penelitian ini adalah suatu sistem penerimaan siswa baru yang sudah ditanyakan langsung pada SMP PGRI Kota Pagaralam. Sistem ini dibangun menggunakan aplikasi macromedia dreamweaverCS3, bahasa pemerograman $P H P$ dan $M y S Q L$, sedangkan metode pengembangan sistemnya adalah Webngineering. Dari penelitian tersebut dapat disimpulkan bahwa untuk membuat website penerimaan siswa baru yang harus dilakukan pertama kali adalah membuat website penerimaan siswa baru. Jika sistem penerimaan siswa baru yang dibangun mampu meng-input data penerimaan siswa baru dan menghasilkan output berupa laporan maka dapat disimpulkan bahwa website penerimaan siswa baru SMP PGRI Kota Pagaralam berhasil.
\end{abstract}

Kata Kunci : Website Penerimaan Siswa Baru SMP PGRI Pagaralam, Web Ngineering, 


\section{PENDAHULUAN}

Sejalan dengan kemajuan ilmu pengetahuan dan teknologi yang semakin pesat, penggunaanya bukanlah hal yang asing lagi bagi masyarakat baik di pedesaan maupun di lingkungan kota sudah banyak yang mampu menggunakan teknologi informasi, kemajuan teknologi informasi saat ini layaknya seperti jamur yang tumbuh di musim hujan tak heran lagi bila anak SD, SMP, dan SMA untuk mengenali dan mempelajari teknologi informasi begitu juga dikalangan mahasiswa, instansi pemerintah maupun swasta yang tidak kalahnya penting dan tidak bisa dipisahkan dengan dunia saat ini.

Berdasarkan hasil dari wawancara dan observasi peneliti yang langsung bertanya kepada operator, bendahara, dan panitia di SMP PGRI Kota Pagaralam sistem yang berjalan masih dilakukan secara manual, terutamap pada penerimaan siswa baru masih dilakukan secara konvensional yaitu calon siswa baru harus datang langsung ke sekolah untuk melakukan pendaftaran, dan data pendaftar masih dicatatat pada buku-buku kemudian disimpan pada rak-rak buku, proses rekap dan membayar registrasi juga masih dilakukan secara manual sehingga sering terjadinya kesalahan data serta memerlukan waktu yang sangat lama untuk mencari data.

Untuk mengatasi masalah tersebut maka sistem yang dilakukan sekarang harus diperbarui dengan melibatkan dalam melakukan sistem penerimaan siswa baru, agar dalam proses-proses yang berjalan dalam sistem tidak terlalu membutukan waktu yang relatif lama. Oleh sebab itu penelitian

mengusulkan sistem penerimaan siswa baru pada SMP PGRI Kota pagaralam dari sistem yang lama ke sistem yang baru dengan menggunakan $P H P$ dan $M Y S Q L$ sebagai databasenya. pemrograman Web. Web adalah suatu layanan informasi yang menggunakan konsep hyperlink yang memudahkan survei melakukan penelusuran informasi melalui internet hal ini yang bertujuan untuk menciptakan suatu penerimaan siswa baru yang lebih cepat dan lebih tersetruktur.

Tujuan dari penelitian ini untuk mereancag dan membangun website penerimaan siswa baru yang dapat mempermuda calon siswa mendaftar dan memantau jumlah pendaftar pada setiap tahun calon siswa yangmendaftara.

\section{METODOLOGI PENELITIAN}

\subsection{Metode Pengumpulan Data}

Dalam rangka mendapatkan data yang diperlukan yang lebih akurat untuk penelitian laporan ini ada beberapa metode yang digunakan yaitu sebagai berikut :

\section{Wawancara (Interview)}

Peneliti mengadakan tanya jawab dengan staf yang bersangkutan, terutama operator komputer SMP PGRI Kota Pagaralam.

\section{Pengamatan Langsung (Observasi)}

Peneliti mengadakan pengamatan secara langsung dengan melakukan penelitian dan peninjaun terhadap permasalahan yang diambil 
ditempat penelitian tepatnya di SMP PGRI Kota Pagaralam.

\section{Studi Literatur}

Yaitu pengumpulan data dari jurnal buku-buku tentang yang ada kaitanya dengan judul peliti. (Rosa A S, 2014 : 141-147).

\subsection{Metode Pengembangan Sitem}

Metode pengembangan sistem salah satu model proses cerdas (sebagai contoh extreme programming, adaptive software devlomen, SCRUM) dapat diaplikasikan pada proses Webe. Agar efektif, setiap teknis harus dapat beradaptasi. Artinya struktur dari tim proyek, model komunikasi diantaranya para anggota tim, kegiatan teknis dan pekerjanpekerjaan yang dilakukan, informasi yang dikumpulkan dan dibuat dalam metode-metode yang digunakan, jadwal proyek dan kendala dan masalah yang harus dipecahkan. (Rohman Taufiq, $2013: 183-185$ )

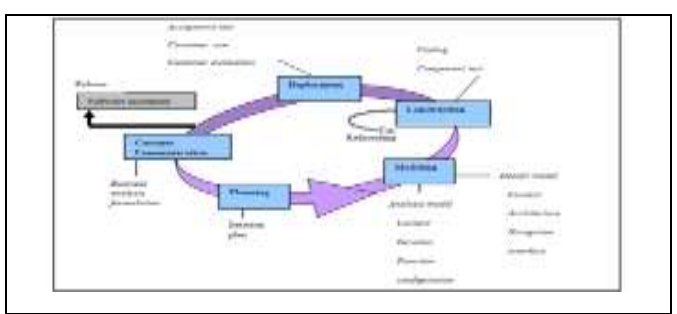

Gambar 1. Tahapan-Tahapan Proses Web

\section{Engineering}

\section{a. Customer Comunication}

Komunikasi dengan pengguna.Pada proses Webe, komunikasi dengan pengguna dikarakteristikan dengan dua aktivitas utama: analisa bisnis dan formulasi.analisis bisnis didefinisikan berkaitan dengan koneksi bisnis/organisasi yang berkaitan dengan WebApp. Selanjutnya, stakeholders didentifikasikan, perubahan iklim bisnis yang potinsial atau permintaan pasar dipridiksi, dan integrasi antara WebApp dan aplikasi bisnis lainya, database, dan fungsi didefinisikan.

\section{b. Planning}

Perencanaan proyek peluncuran WebApp dilakukan, perencanaanya dilakukan terdiri dari definisi tugas dan jadwal pekerjaan untuk jangka waktu tertentu, biasanya waktu mingguan. Yang diproyeksikan untuk peluncuran Webapp.

\section{c. Modeling}

Teknik

softwerkonvensional menganalisa dan mendasin tugas yang didapatkan untuk menggembangkan WebApp, menggabungkan, dan kemudian menyatukanya dalam kegiatan pemodelan Webe. Tujuanya adalah untuk mengembangkan analisa "cepat" dan mendesain model yang akan mendapatkan kebutuhan dan pada waktu yang sama merepresentasikan sebuah WebApp yang akan memuaskan mereka.

\section{d. Construction}

Perangkat webe dan teknologinya diaplikasikan untuk membuat WebApp yang telah dijadikan model. Pada saat WebApp telah dibuat serangkaian tes yang cepat dilakukan untuk mengukur kesalahan dalam desain tersebut.

\section{e.. Deployment}

WebApp dikonfigurasikan untuk lingkup operasionalnya, diluncurkan pada para pengguna akhir, dan kemudian adanya tahap evaluasi. Umpan balik disaikan pada timWebe, dan perbaikan dilakukan sesuai kebutuhan. 


\subsection{PengertianWebsite}

Website merupakan komponekomponen yang dapat menyusun sebuah aplikasi web. Komponen di identic dengan perangkat lunak dan bahasa pemerograman yang digunakan untuk membuat aplikasi web baik web statis maupun web dinamis. (Arief M. r., 2011 : 19). Sedangkan menurut $M$. Rudianto Arief, (2011: 7) Website adalahsalah satu aplikasi yang berisikan dokumendokumen multimedia (teks, gambar, suara, animasi, video) didalamnya yang menggunakan protocol HTTP (hypertext transfer protocol) dan untuk mengaksisnya penggunaan perangkat lunak yang disebut browser.

\subsection{Web Server}

Merupakan program aplikasi yang memiliki fungsi sebagai tempat menyimpan dokumen-dokumen web. Semua dokumen web baik yang ditulis menggunakan client side scripting maupun server side scripting tersimpan di dalam direktori utama web server (document root), Berikut adalah beberapa contoh web server: web server apache yang mendukung $P H P$, web serverMicrosop InternetInformasi Server (IIS) yang mendukung ASP dan PHP, webserver Apache Tomcat yang mendukung java server pages (JSP) . (Arief M. R., 2011 : 21). Web Server adalah penyedia halaman web, merupakan perangkat lunak yang dapat menyajikan halaman web kepada browser jika meminta halaman tersebut (apabila browser melakukan HTTPrequest), Perangkat lunak webserver dapat juga dijadikan tempat untuk meletakan file-file halaman web dan dapat juga dijadikan tempat dilakukanya interpretasi scriptcriptbprogram yang dituliskan menggunakan programan server-side. (Utomo, $2011: 273)$.

\subsection{Struktut Tabel}

Adapun table-tabel atau file-file yang akan dibangun dan mempunyai struktur file sebagai berikut:

\subsubsection{Tabel Pendaftaran}

Tabel 1. Tabel Pendaftaran

\begin{tabular}{|c|c|c|c|c|}
\hline No & Name & Type & size & Ket \\
\hline 1 & $\begin{array}{l}\text { No_pen } \\
\text { daftaran } \\
*\end{array}$ & Int & 11 & $\begin{array}{l}\text { No } \\
\text { pendaftar }\end{array}$ \\
\hline 2 & Nama & $\begin{array}{l}\text { Varcha } \\
r\end{array}$ & 50 & Nama \\
\hline 3 & $\mathrm{Nis}$ & $\begin{array}{l}\text { Varcha } \\
r\end{array}$ & 50 & $\begin{array}{l}\text { Nomor } \\
\text { induk } \\
\text { siswa }\end{array}$ \\
\hline 4 & $\begin{array}{l}\text { Asal } \\
\text { Sekolah }\end{array}$ & $\begin{array}{l}\text { Varcha } \\
r\end{array}$ & 50 & $\begin{array}{l}\text { Asal } \\
\text { Serkolah }\end{array}$ \\
\hline 5 & $\begin{array}{l}\text { Jenis_k } \\
\text { elamin }\end{array}$ & $\begin{array}{l}\text { Varcha } \\
r\end{array}$ & 20 & Alamat \\
\hline 6 & $\mathrm{Ttl}$ & $\begin{array}{l}\text { Varcha } \\
r\end{array}$ & 50 & $\begin{array}{l}\text { Tempat } \\
\text { tanggal } \\
\text { lahir }\end{array}$ \\
\hline 7 & Agama & $\begin{array}{l}\text { Varcha } \\
r\end{array}$ & 15 & Agama \\
\hline 8 & $\begin{array}{l}\text { Kewarg } \\
\text { anegara } \\
\text { an }\end{array}$ & $\begin{array}{l}\text { Varcha } \\
r\end{array}$ & 30 & $\begin{array}{l}\text { Kewarga } \\
\text { negaraan }\end{array}$ \\
\hline 9 & $\begin{array}{l}\text { Anak_k } \\
\text { e }\end{array}$ & $\begin{array}{l}\text { Varcha } \\
r\end{array}$ & 15 & Anak ke \\
\hline 10 & $\begin{array}{l}\text { Tempat } \\
\text { _tinggal }\end{array}$ & $\begin{array}{l}\text { Varcha } \\
r\end{array}$ & 30 & $\begin{array}{l}\text { Tempat } \\
\text { tinggal }\end{array}$ \\
\hline 11 & $\begin{array}{l}\text { No_telp } \\
\text { on }\end{array}$ & $\begin{array}{l}\text { Varcha } \\
r\end{array}$ & 15 & $\begin{array}{l}\text { Nomor } \\
\text { telpon }\end{array}$ \\
\hline 12 & $\begin{array}{l}\text { Golong } \\
\text { an_dara } \\
\mathrm{h}\end{array}$ & $\begin{array}{l}\text { Varcha } \\
r\end{array}$ & 2 & $\begin{array}{l}\text { Golonga } \\
\text { n darah }\end{array}$ \\
\hline
\end{tabular}




\begin{tabular}{lllll}
\hline 13 & $\begin{array}{l}\text { Nama_ } \\
\text { ayah }\end{array}$ & $\begin{array}{l}\text { Varcha } \\
r\end{array}$ & 50 & $\begin{array}{l}\text { Nama } \\
\text { ayah }\end{array}$ \\
\hline 14 & $\begin{array}{l}\text { Nama_i } \\
\text { bu }\end{array}$ & $\begin{array}{l}\text { Varhca } \\
r\end{array}$ & 50 & $\begin{array}{l}\text { Nama } \\
\text { ibu }\end{array}$ \\
\hline 15 & $\begin{array}{l}\text { Pekerja } \\
\text { an_aya } \\
\text { h }\end{array}$ & $\begin{array}{l}\text { Varcha } \\
r\end{array}$ & 50 & $\begin{array}{l}\text { Pekerjaa } \\
\text { n ayah }\end{array}$ \\
\hline 16 & $\begin{array}{l}\text { Pekerja } \\
\text { an_ibu }\end{array}$ & $\begin{array}{l}\text { Varcha } \\
r\end{array}$ & 50 & $\begin{array}{l}\text { Pekeraan } \\
\text { ibu }\end{array}$
\end{tabular}

*Primary key

\subsubsection{Tabel Hasil Tes}

Tabel 2. Tabel Hasil Tes

\begin{tabular}{cllll}
\hline No & Name & Type & size & Ket \\
\hline 1 & $\begin{array}{c}\text { Id_hasil } \\
\text { test* }\end{array}$ & Int & 11 & $\begin{array}{l}\text { Id hasil } \\
\text { test }\end{array}$ \\
\hline 2 & $\begin{array}{l}\text { No_pen } \\
\text { daftaran }\end{array}$ & $\begin{array}{l}\text { Varc } \\
\text { har }\end{array}$ & 15 & $\begin{array}{l}\text { No } \\
\text { pendaftar } \\
\text { an }\end{array}$ \\
\hline 4 & Nilai & $\begin{array}{l}\text { Varc } \\
\text { har }\end{array}$ & 15 & $\begin{array}{l}\text { Rata-rata } \\
\text { Nilai }\end{array}$ \\
*Primary key & & &
\end{tabular}

\subsubsection{Tabel Pengumuman}

Tabel 3. Tabel Pengumuman

\begin{tabular}{lllll}
\hline No & Name & Type & size & Ket \\
\hline 1 & $\begin{array}{l}\text { Id_pen } \\
\text { gumum } \\
\text { an* }\end{array}$ & Int & 11 & $\begin{array}{l}\text { Id } \\
\text { persyarat } \\
\text { an }\end{array}$ \\
\hline 1 & Judul & $\begin{array}{l}\text { Varch } \\
\text { ar }\end{array}$ & 30 & Judul \\
\hline 2 & $\begin{array}{l}\text { Isi_pen } \\
\text { gumum } \\
\text { an }\end{array}$ & Text & $\begin{array}{l}\text { Isi } \\
\text { pengumu } \\
\text { man }\end{array}$ \\
\hline 3 & $\begin{array}{l}\text { Tangga } \\
1\end{array}$ & $\begin{array}{l}\text { Varch } \\
\text { ar }\end{array}$ & 20 & Tanggal \\
\hline
\end{tabular}

*Primary key

\subsubsection{Tabel Jadwal Tes}

Tabel 4. Tabel Jadwal Tes

\begin{tabular}{lllll}
\hline No & Name & Type & size & Ket \\
\hline 1 & Id_jad & Int & 11 & Id \\
\hline
\end{tabular}

\begin{tabular}{cllll}
\hline & $\begin{array}{l}\text { wal_te } \\
\text { st* }\end{array}$ & & $\begin{array}{l}\text { jadwal } \\
\text { test }\end{array}$ \\
\hline 2 & $\begin{array}{l}\text { No_pe } \\
\text { ndaftar } \\
\text { an* }\end{array}$ & $\begin{array}{l}\text { Varcha } \\
r\end{array}$ & 15 & $\begin{array}{l}\text { Nomor } \\
\text { pendafta } \\
\text { r }\end{array}$ \\
\hline 3 & $\begin{array}{l}\text { Ruang } \\
\text { test }\end{array}$ & $\begin{array}{l}\text { Varcha } \\
\text { - 50 }\end{array}$ & $\begin{array}{l}\text { Ruang } \\
\text { test }\end{array}$ \\
\hline 4 & $\begin{array}{l}\text { Tangga } \\
\text { 1_test }\end{array}$ & $\begin{array}{l}\text { Varcha } \\
\text { 1 50 }\end{array}$ & $\begin{array}{l}\text { Tanggal } \\
\text { test }\end{array}$ \\
\hline *Primary key & & &
\end{tabular}

\subsection{Desain Input}

Masukan Input merupakan awal dimulainya proses informasi, masukan aplikasi pengolahan data adalah data yang merupakan bahan menta dari informasi perancangan masukan, merupakan rancangan dari form yang digunakan untuk menangkap data, kodekode input yang digunakan dari bentuk tampilan input.

\subsubsection{Desain Menu Utama Website}

Perancangan menu utama Website dan menu, dibuat agar penampilan program ini lebih baik menarik selintas program dapat dilihat gambar berikut ini:

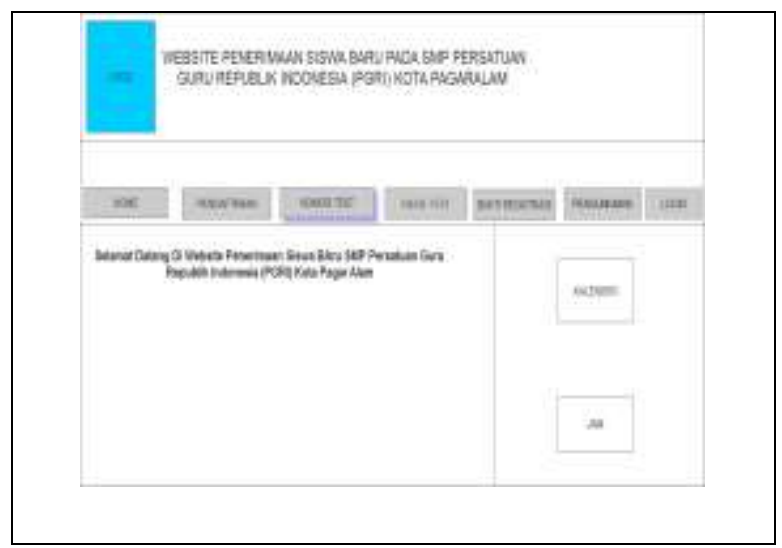

Gambar 2. Desain Menu Utama Website

\subsubsection{Desain Menu Pendaftaran}

Pada desain data pendaftaran adalah inputan data-data pendaftaran yang bisa kita 
lihat, tambah, edit, hapus, simpan, cari pendaftaran di botoon-botoon yang ada pada tampilan.

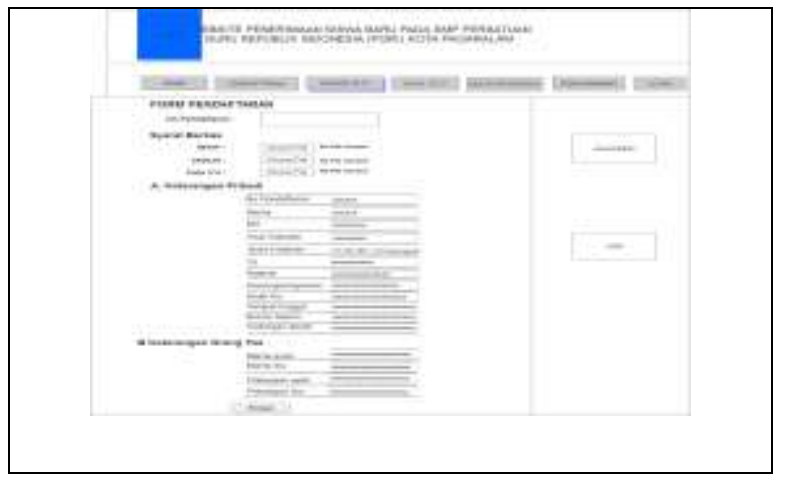

Gambar 3. Desain Menu Pendaftaran

\subsubsection{Desain Nomor Test}

Pada desain ini akan menampilkan nomor tes, setelah user telah mengisi data pendaftaran .dan user akan mendapatkan nomor tes

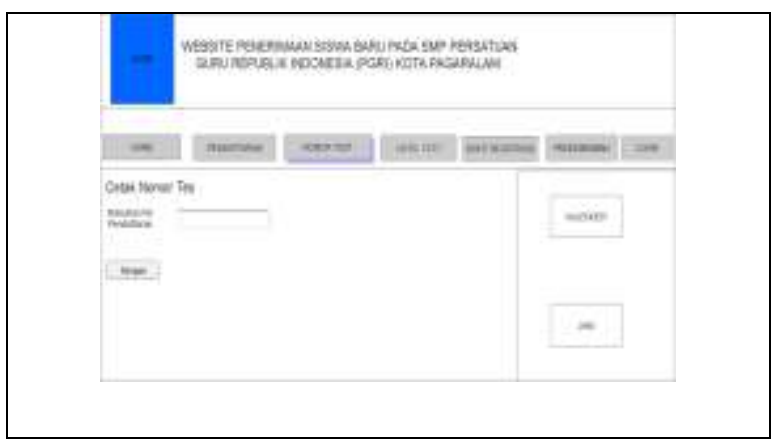

Gambar.4. Desain Nomor Test

\subsubsection{Desain Hasil Test}

Pada desain ini akan menampilkan hasil tes. Apabila admin sudah menginputkan data hasil tes dan user dapat melihat hasil tes.

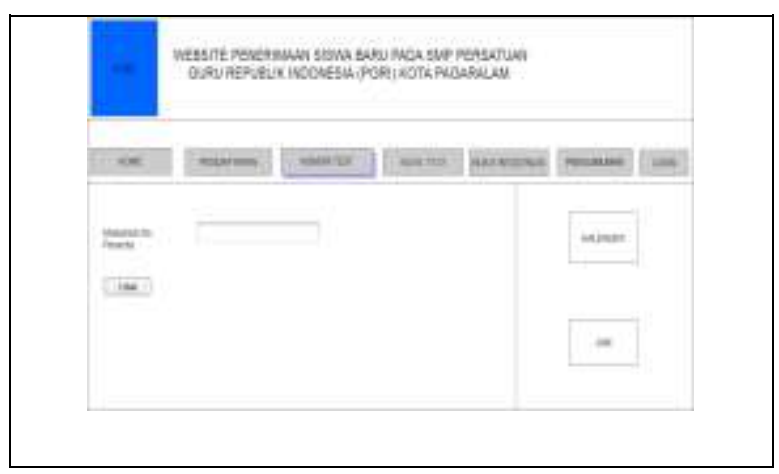

\section{Gamba.5. Desain Hasil Test}

\subsubsection{Desain Bukti Registrasi}

Pada desain ini hanya menampilkan data registrasi saja, apabila user sudah membayar registrasi.

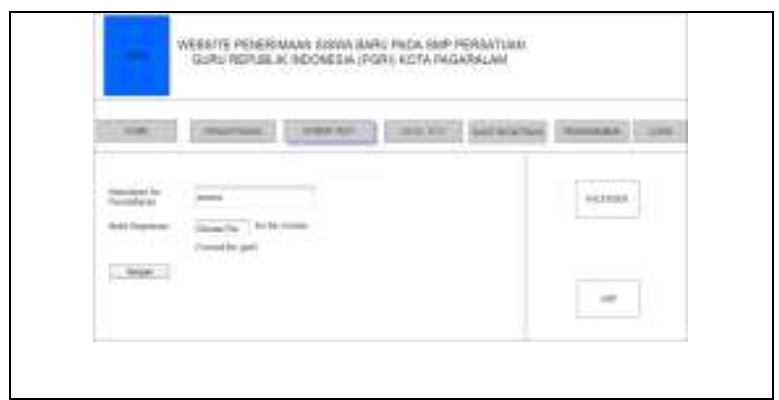

\section{Gambar .6. Desain Bukti Registrasi}

\subsubsection{Desain Data Pengumuman}

Pada desain ini akan menampilkanpengumuman. apabila admin sudah menginputkan data persyaratan. dan user dapat melihat data pengumuman yang akan di bawa saat ujian.

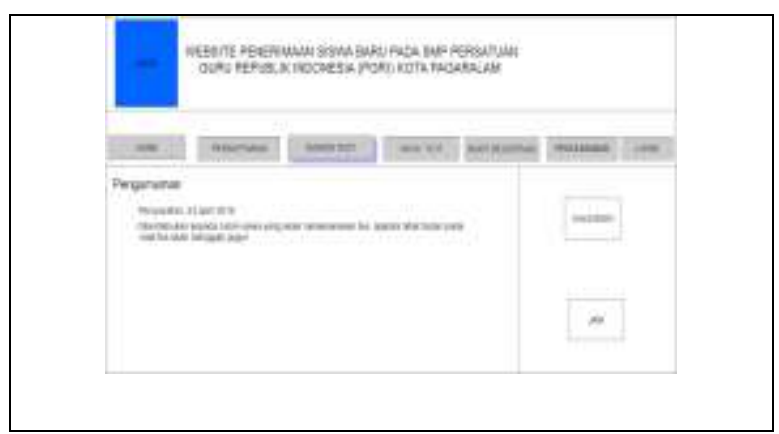

Gambar 7. Desain Pengumuman 


\section{HASIL DAN PEMBAHASAN}

\subsection{Hasil}

Pada penelitian yang penulis lakukan di sekolah SMP PGRI Kota Pagaralam menghasilkan suatu website penerimaan siswa baru dengan menggunakan bahasa pemerograman $P H P$ dan $M Y S Q L$ yang berguna untuk mencari data website penerimaan siswa baru SMP PGRI Kota Pagaralam.

Implementasi sistem merupakan langka-langka yang dilakukan dalam menyelesaikan desain sistem yang telah disetujui untuk menguji menginstasi dan memulai sistem yang baru diperbaiki untuk mengantikan sistem yang lama.

Tujuan dari implementasi sistem yaitu :

1. Menyelesaikan desain sistem yang ada dalam dokumen desain sistem yang teruji, menyusun dokumen-dokumen yang diperbaiki.

2. Menulis, me nguji dan medokumentasikan sistem programprogram dan prosedur-prosedur yang diperbaiki oleh desain sistem yang disetujui.

3. Memastikan bahwa user dapat mengoprasikan sistem yang baru.

4. Mematikan bahwa sistem memenuhi permintakaan user yaitu dengan menguji sistem secara menyeluru.

\subsection{Pembahasan}

Cara mengoperasikan website penerimaan siswa baru yaitu :
1. Terlebih dahulu aktikan $>X a m p p>$ lalu pilih dan klik XamppControl Panel.

2. Maka akan tampil windos "Xampp Control Panel Application.

3. PAda pilihan "Modules", klik button star untuk apache dan Mysql.

4. Web Server dan database server telah aktif.

5. Setelah Web server dan database server telah aktif, aktifkan Mozilla Firefok lalu panggil localhose/pgri $\mathrm{OK}$

6. Maka akan tampil website penerimaan siswa baru SMP PGRI Kota Pagaralam.

7. Ini alamat Website SMP PGRI “https:/nini-

\section{karlina.000webhostapp.com"}

Sehingga akan menghasilkan beberapa tampilan berikut ini.

\subsubsection{Halaman Menu Utama Website}

Halam utama merupakan halaman awal yang tampilkan pada saat User membuka Website Penerimaan Siswa Baru SMP PGRI Kota Pagaralam. Halaman ini memmuat menu login, dan menu navigasi ke halaman utama. Tampilan halaman utama dapat dilihat pada gambar di bawah ini.

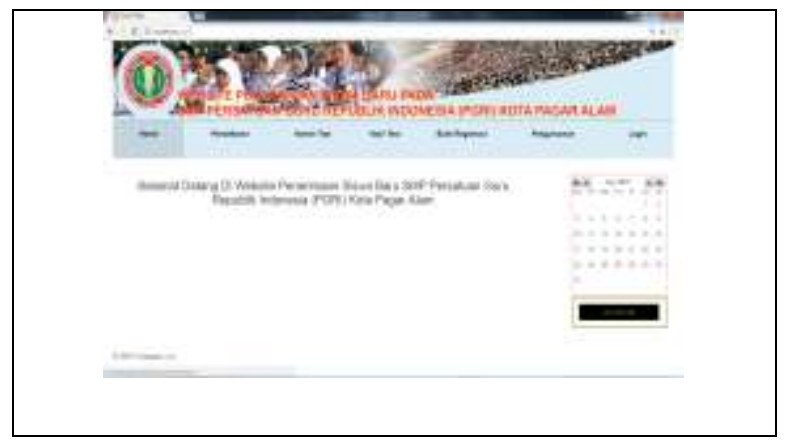

Gambar 8. Halaman Menu Utama Website 


\subsubsection{Halaman Menu Umum User}

Halam utama merupakan halaman awal yang tampilkan pada saat User membuka Website Peneriman Siswa Baru SMP PGRI Kota Pagaralam. Tampilan halaman utama dapat dilihat pada gambar di bawah ini.

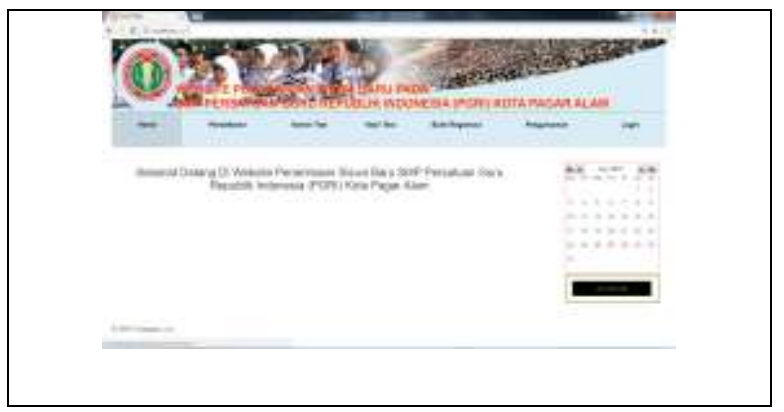

Gambar 9. Halaman Menu Utama User

\subsubsection{Halaman Menu Pendaftaran}

Pada halaman menu utama ini akan menampilkan inputan data pendaftaran pada calon siswa yang akan mengisi data yang lengkap agar siswa bisa mendapatkan no test.

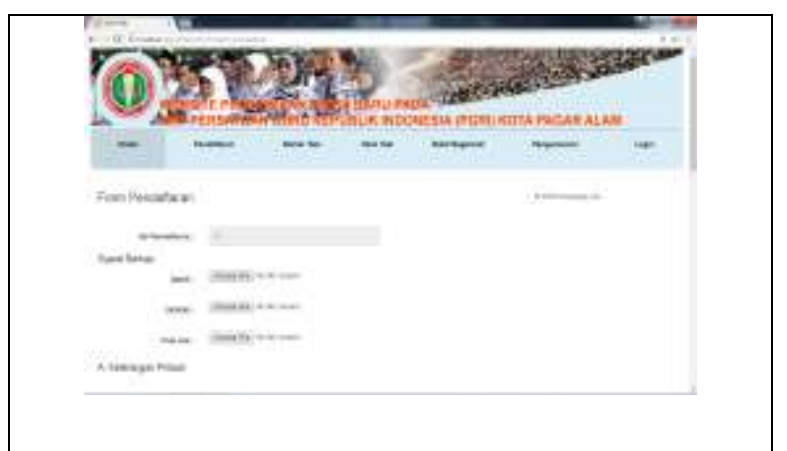

Gambar 10. Halaman Menu Pendaftaran

\subsubsection{Halaman Nomor Test}

Pada halaman lihat nomor test ini akan menampilkan hasil inputan data pendaftaran dan siswa bisa mengikuti test, yang telah di inputkan oleh admin untuk user bisa melihat nomor untuk mengikkuti test pada SMP PGRI.

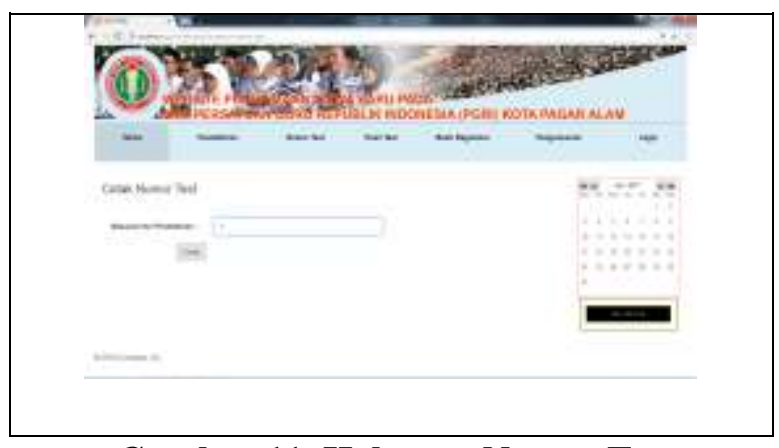

Gambar 11. Halaman Nomor Tes

\subsubsection{Halaman Hasil Test}

Pada halaman hasil test ini akan menampilkan hasi test yang telah diinputan oleh admin hasil tes, agar bisa user melihat nilai atau keterangan lulus atau tidak lulus pada sekolah SMP PGRI Kota Pagaralam.

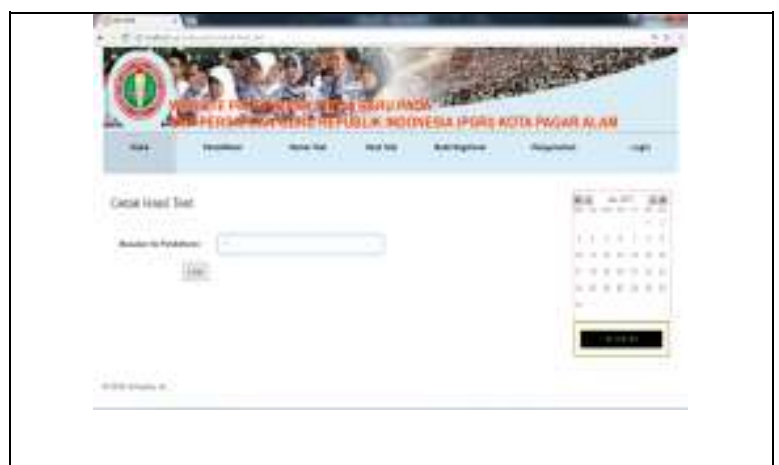

\section{Gambar 12. Halaman Hasil Tes}

\subsubsection{Halaman Bukti Registrasi}

Pada halaman bukti registrasi ini akan menampilkan hasil data pembayaran siswa yang telah registerasi, disini admin bisa meliaht bukti berupa gambar, word, dan $p d f$ setelah siswa ditetapkan sudah masuk SMP PGRI Kota Pagaralam. 


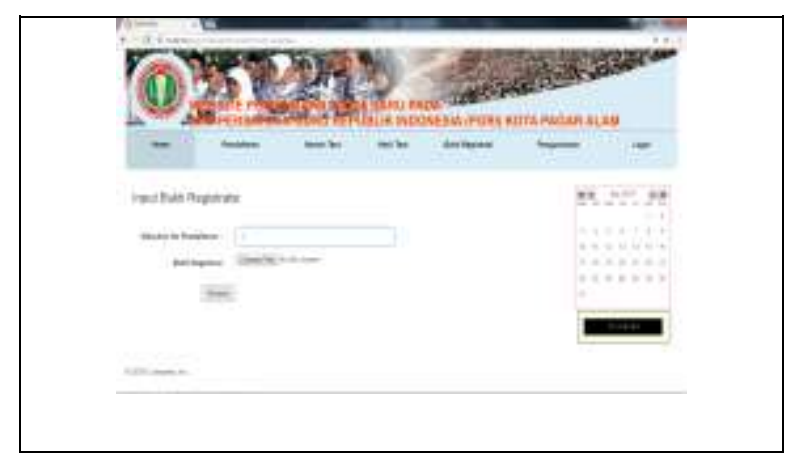

Gambar 13. Halaman Bukti Registrasi

\subsubsection{Halaman Pengumuman}

Pada halama pengumuman ini akan menampilkan hasil pengumuman yang telah diberitahukan oleh sekolah untuk user untul melihat tentang SMP PGRI Kota Pagaralam, apa yang ada di SMP PGRI.

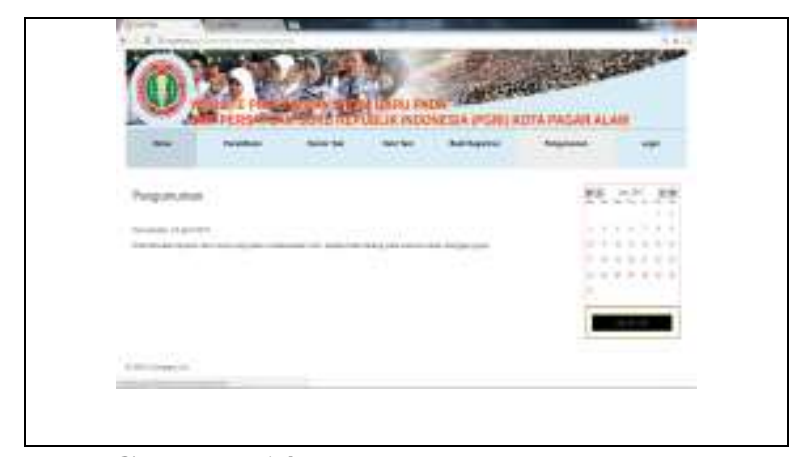

Gambar 14. Halaman Pengumuman

\section{KESIMPULAN}

Dalam penulisan ini telah diuraikan bagaimana website penerimaan siswa baru pada SMP PGRI kota Pagaralam, maka peneliti dapat menyimpulkan bahwa website penerimaan siswa baru pada SMP PGRI Kota Pagaralam, dapat membantu calon siswa dalam melakukan pendaftaran tampa melakukan datang langsung ke sekolah untuk mendaftar.

\section{DAFTAR PUSTAKA}

Arief, M. R. (2011). Pemerograman Web Dinamis Menggunakan PHP dan Mysql. Yogyakarta: Andi.

Enterprise, J. (2014). MYSQL untuk pemula. yogyakarta: pt elex media kompution.

Miftahus sholihin, S. m. (2014). sistem penerimaan peserta didik baru berbasis wew (Online) di SMK Muhammadiyah 7 kedugpring.

Putri, L. D. (2014). Perancangan Sistem Informasi Penerimaan Siswa Baru Pada Sekolah Menengah Kejuruan Negeri 3 Pacitan.

Rohman Taufiq, S. (2013). Sistem Informasi Manajemen. Yogyakarta.

Rosa A S, M. S. (2014). Rekayasa perangkat lunak tersetruktur dan berorentasi objek. Bandung: Informatika.

Sulistianingsih, D. (2012). Sistem Informasi Penerimaan Siswa Baru Berbasis Web Pada Sekolah Menengah Kejuruan (SMK) Pgri Donorojo.

Teguh nurhadi suharsono, W. r. (2015).

Perangkat lunak penerimaan siswa baru (PSB) online SMA negri 1 beleendah.

Utomo, A. A. (2011). Kamus Teknologi Informasi Komunikasi. Yogyakarta: Sri Wulandari M. 